\title{
Morphologic Effects of Filiform Papilla Root on the Lingual Mechanical Functions of Chinese Yellow Cattle
}

\author{
Efectos Morfológicos de las Raíces de las Papilas Filiformes \\ sobre la Función Mecánica Lingual del Ganado Amarillo Chino
}

Jun Fu*; Zhihui Qian* \& Luquan Ren*

FU, J.; QIAN, Z. \& REN, L. Morphologic effects of filiform papilla root on the lingual mechanical functions of Chinese yellow cattle. Int. J. Morphol., 34(1):63-70, 2016.

SUMMARY: The morphology of filiform papilla root in the tongue of Chinese yellow cattle were studied by scanning electron microscopy, and several geometric models were established to analyze the possible effects of such structures on lingual mechanical functions. Conical and tongue-like filiform papillae were detected in different locations on the lingual surface, along with six types of root structures. A lingual groove surrounded the papillae in five of these structures. To date, such grooves have not been discussed in studies on bovine lingual morphology, and those distributed on the dorsal surface of the lingual apex can limit the motion ranges of filiform papillae. Two secondary papillae emerged from a groove on the dorsal surface of the lingual apex's caudal half; these papillae can protect a filiform papilla root from damage. The grooves and the flat orientation of such papillae on the dorsal surface of the lingual body can reduce energy expenditure during forage transportation. A lingual rib that can strengthen the filiform papilla root emerged from a groove on the dorsal surface of the rostral half of the lingual body. On the dorsal surface of the lingual body's caudal half, all filiform papillae emerged from a groove to form low lingual walls that can protect the roots from being crushed by forage. High lingual walls were generated on the lateral surface of the lingual apex; these walls enable filiform papillae to adapt to harsh food environments effectively. The root structures on the lingual body's lateral surface were adequately simple and did not exhibit lingual grooves; thus, hydraulic resistance may decrease during mastication. Diverse root structures can optimize the lingual mechanical functions and improve self-protection capability in combination with the appearance and distributions of these papillae. All the aforementioned features may be the result of environmental adaption and cattle evolution.

KEY WORDS: Morphology; Root structure; Filiform papillae; Mechanical function; Tongue.

\section{INTRODUCTION}

Chinese yellow cattle (Bos taurus) are among the most important domestic animals in China and serve as a rich source of meat and leather for people (Cai et al., 2014). These bovines are typical ruminants and play with their tongues more frequently than other domestic animals do. The role of the tongue in the feeding process is significant in conjunction with those of other organs, including the upper jaw that is within and near the oral cavity (Iwasaki, 2002). The functions of the tongue are related to the morphology, structure, and distribution of the lingual papillae (Scala $e t$ al., 1995). In bovines, these papillae are usually classified into gustatory and mechanical papillae according to their functions (Chamorro et al., 1986; de Paz Cabello et al., 1988). Moreover, filiform, conical, and lenticular papillae are closely related to the mechanical functions of the tongue (de Paz Cabello et al.); in particular, filiform papillae are the largest and most widespread papillae in bovine tongues. These papillae are related to feeding functions, such as prehension, transportation, mastication, and food manipulation (Scala et al., 1995; Shao et al., 2010; Sato et al., 1994).

Various studies with light and scanning electron microscopy have been conducted on the histological and morphological features of filiform papillae in bovines, such as cows (Steflik et al., 1983; Chamorro et al.; de Paz Cabello et al.), buffaloes (Scala et al., 1993), Japanese Black cattle (Sato et al., 1994), Zavot cattle (Sari et al., 2010), yaks (Shao et al.; Wang et al., 2015), and domestic cattle (Scala et al., 1995). Extensive morphologic research has also been presented on the filiform papillae in other ruminant species and breeds, including Formosan serows (Atoji et al., 1998),

* Key Laboratory of Bionic Engineering (Ministry of Education), Jilin University, Changchun, China. 
Blackbucks (Emura et al., 1999), Barbary sheep (Emura et al., 2000), Saanen goats (Kurtul \& Atalgın, 2008), goitered gazelles (Harem et al., 2011), chital deer (Erdogan \& Pérez, 2014), giraffes (Emura et al., 2013), one-humped camels (El Sharaby et al., 2012), and Bactrian camels (Eerdunchaolu et al., 2001). These previous works have reported on the orientations, distributions, appearances, ultrastructures and functions of such papillae. To date, however, the morphology of the filiform papilla root located in different areas of the bovine tongue has not been examined extensively. These structures may significantly affect the mechanical functions of tongue.

Therefore, the objective of this study was to investigate the morphologic characteristics of filiform papilla root in the tongue of Chinese yellow cattle by scanning electron microscopy and to compare the findings with those reported for related ruminants. Finally, the morphologic effects of filiform papilla root on the mechanical functions of tongue were analyzed.

\section{MATERIAL AND METHOD}

All the research subjects employed in the current experiments were approved by the Animal Ethics Committee of Jilin University, China. The tongues of six healthy adult Chinese yellow cattle (four males and two females) with a mean weight of $305 \pm 20 \mathrm{~kg}$ were collected immediately after slaughter from the Haoyue slaughter house, Changchun City, Jilin Province, China (121 ${ }^{\circ}-124^{\circ} 22^{\prime} \mathrm{E}$; $\left.44^{\circ} 13^{\prime}-46^{\circ} 18^{\prime} \mathrm{N}\right)$.

The tongues were dissected, and small pieces (approximately $65 \mathrm{~mm}^{2}$ ) were washed in $0.1 \mathrm{M}$ chilled phosphate buffer ( $\mathrm{pH} 7.4$ ), fixed in $2.5 \%$ glutaraldehyde for $6 \mathrm{~h}$, and again washed twice in $0.1 \mathrm{M}$ of the same phosphate buffer. Secondary fixation was performed in $1 \%$ osmium tetroxide for $1 \mathrm{~h}$, and the specimens were dehydrated by acetone. Then, the specimens were critical point-dried and coated with gold palladium; subsequently, they were observed and photographed under a scanning electron microscope (ZEISS EVO 18, Germany). The data were presented as median \pm standard error.

Several geometric models were established based on scanning electron microscopy observations to analyze the possible morphologic influence of filiform papilla root on lingual mechanical functions. Given its robust and slender features, the conical filiform papilla was simplified into rod form, whereas the flat tongue-like filiform papilla was considered in plate form. In addition, the forage unit was simplified into ball form based on its physical characteristics.

\section{RESULTS}

The tongue was divided into three sections, i.e., the lingual apex, body, and root (Fig. 1). Numerous filiform papillae were distributed on the dorsal and lateral surfaces of the lingual apex and body, respectively. Furthermore, the features of filiform papillae, including diameter, height, and angle, varied with location (as shown in Table I).

Root structures of filiform papillae on dorsal surface: Each filiform papilla root was surrounded by a lingual groove on the dorsal surface of the lingual apex (Fig. 2). A clearance between the lingual groove and the filiform papilla root was observed on the rostral half (Fig. 2b). Two secondary papillae emerged from the lingual groove on the caudal half and were distributed on the two lateral sides of the filiform papilla root (Fig. 2d). In addition, all filiform papillae were robust, conical, and oriented caudally on the dorsal surface of the lingual apex (Figs. $2 \mathrm{a}$ and $2 \mathrm{c})$.

A lingual groove also encircled each filiform papilla root on the dorsal surface of the lingual body (Fig. 3). A lingual rib emerged from the groove on the rostral half and connected with the filiform papilla root (Fig. 3b). The filiform papilla emerged from the groove on the caudal half; consequently, a low lingual wall was formed (Fig. $3 \mathrm{~d})$. In addition, all the filiform papillae were tonguelike in appearance and were laid almost flat on the dorsal surface of the lingual body (Figs. 3a and 3c).

Root structures of filiform papillae on lateral surface: The root structures of the filiform papillae on the lateral surface of the lingual apex were similar to those on the dorsal surface of the caudal half of the lingual body (Figs. $3 \mathrm{~d}$ and $4 \mathrm{~b}$ ). Each filiform papilla root was surrounded by a lingual groove (Fig. 4b). A lingual wall was generated as well; this wall was apparently higher than that on the dorsal surface of the caudal half of the lingual body (Fig. 4b). The filiform papillae distributed in this location were also tongue-like and laid almost flat (Fig. 4a).

The root structures of the filiform papillae on the lateral surface of the lingual body were markedly different from the five types described above. These papillae emerged from the lateral surface of the tongue, and the root structure was simple (Fig. 4d). No lingual groove, rib, secondary papilla, or wall surrounded the filiform papilla root. In addition, the filiform papillae in this location were slender, conical, and laid almost flat (Fig. 4c). 
Table I. The measurement data of filiform papillae according to locations (Mean \pm SE).

\begin{tabular}{lccc}
\hline Locations & Diameter at the base $(\boldsymbol{\mu m})$ & Height $(\boldsymbol{\mu m})$ & Angle $\left(^{\circ}\right)$ \\
\hline Dorsal surface of rostral half of lingual apex & $551.68 \pm 26.17$ & $2105.26 \pm 206.32$ & $38.86 \pm 2.01$ \\
Dorsal surface of caudal half of lingual apex & $592.49 \pm 48.46$ & $1864.43 \pm 140.61$ & $34.69 \pm 1.57$ \\
Dorsal surface of rostral half of lingual body & $521.05 \pm 22.81$ & $1339.47 \pm 50.76$ & $6.02 \pm 0.19$ \\
Dorsal surface of caudal half of lingual body & $230.02 \pm 16.21$ & $558.49 \pm 45.80$ & $5.81 \pm 0.17$ \\
Lateral surface of lingual apex & $227.09 \pm 22.00$ & $691.85 \pm 70.88$ & $4.86 \pm 0.13$ \\
Lateral surface of lingual body & $194.40 \pm 14.76$ & $827.10 \pm 44.27$ & $3.21 \pm 0.11$
\end{tabular}

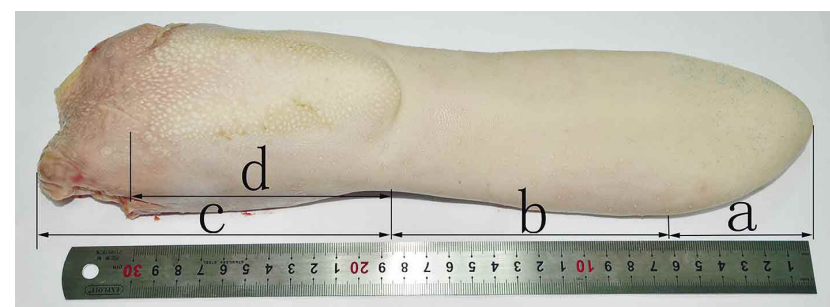

Fig. 1. Macrograph of the tongue of Chinese yellow cattle. a, lingual apex; b, lingual body; c, lingual root; d, lingual torus.

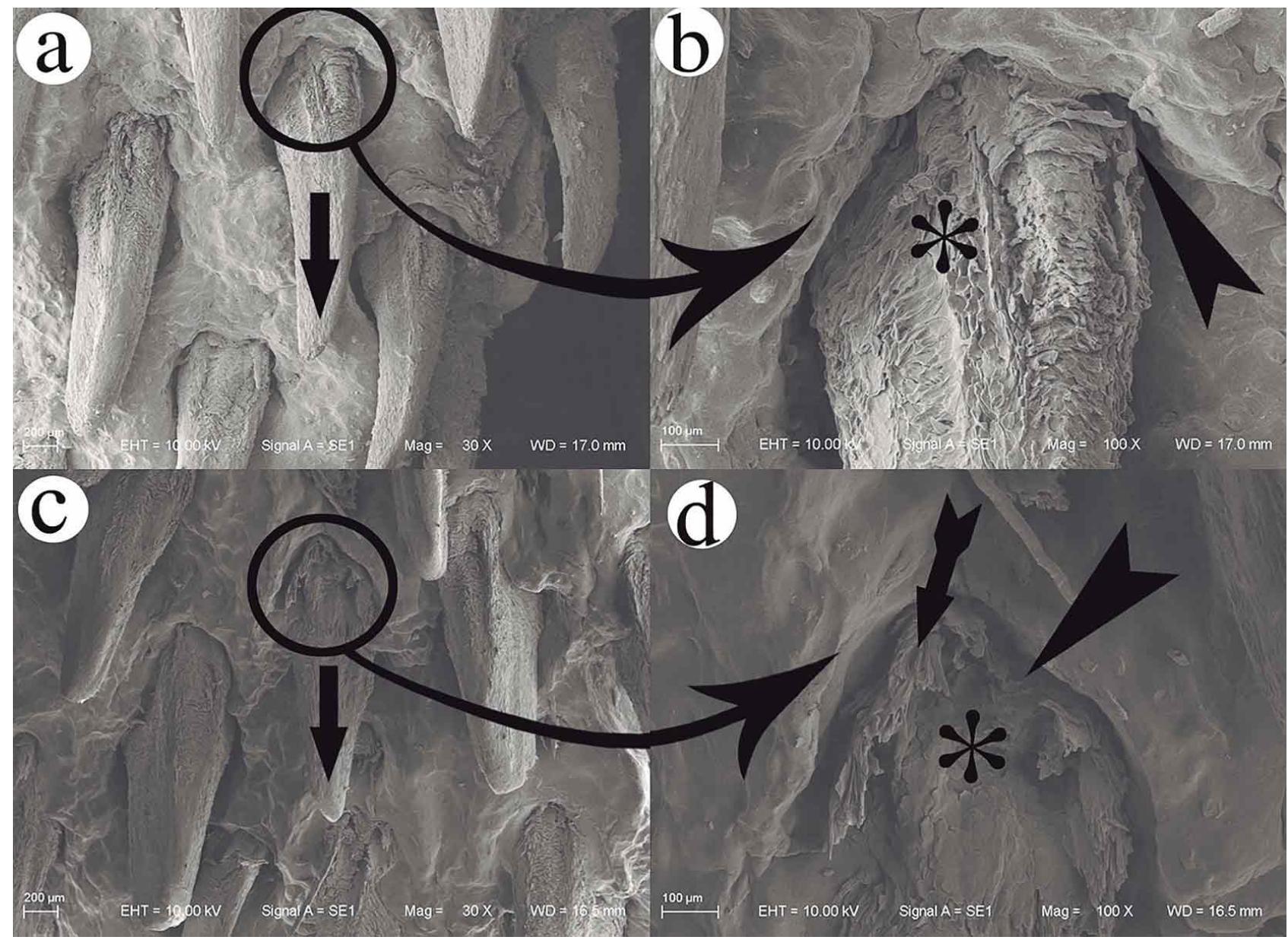

Fig. 2. Filiform papillae on the dorsal surface of the lingual apex. (a) Morphology of filiform papillae on the rostral half. (b) Structure of filifrom papilla root on the rostral half. (c) Morphology of filiform papillae on the caudal half. (d) Structure of filifrom papilla root on the caudal half. arrow, conical filiform papilla; arrowhead, lingual groove; dart arrow, secondary filiform papilla; star, filiform papilla root. 


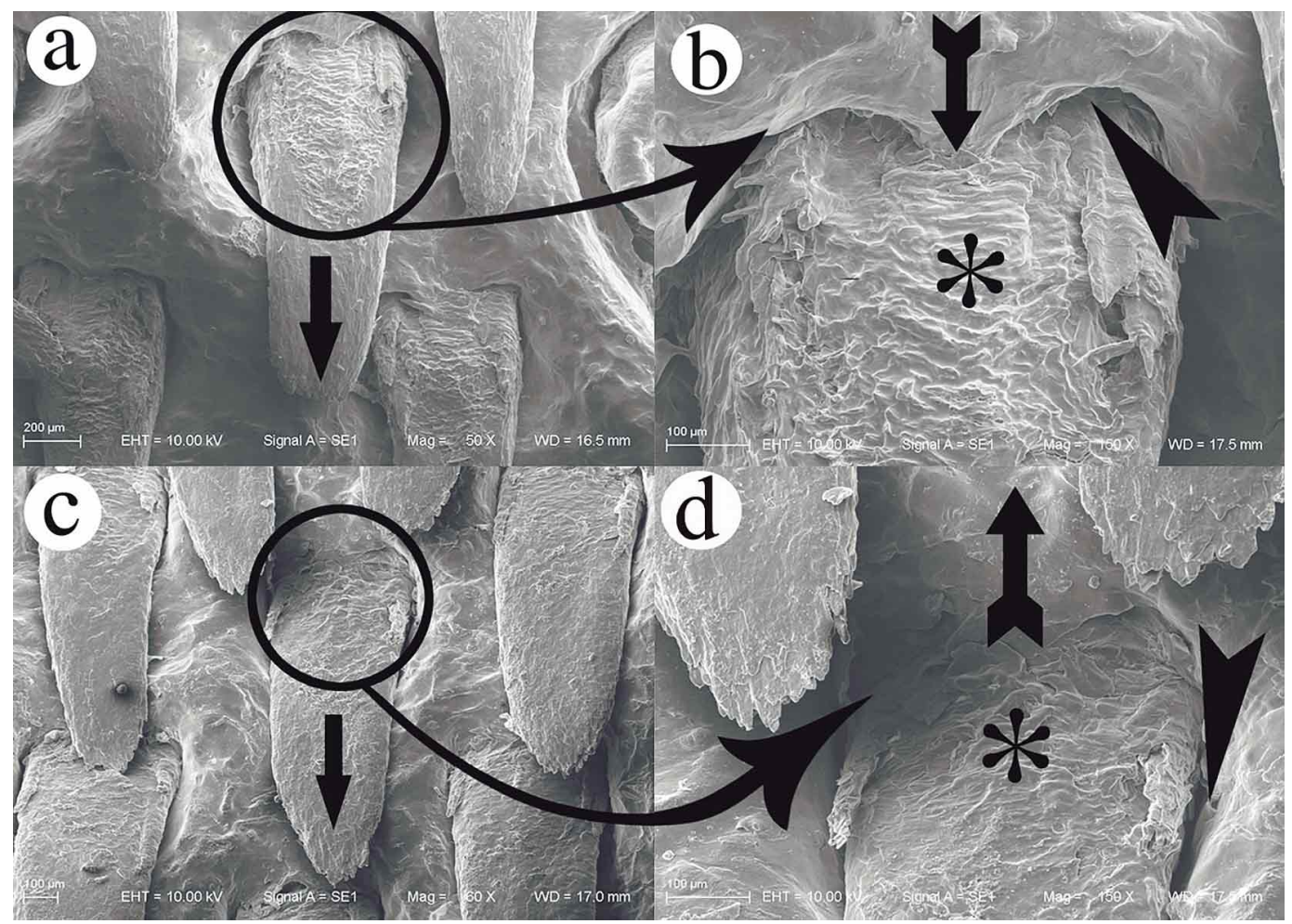

Fig. 3. Filiform papillae on the dorsal surface of the lingual body. (a) Morphology of filiform papillae on the rostral half. (b) Structure of filifrom papilla root on the rostral half. (c) Morphology of filiform papilla on the caudal half. (d) Structure of filifrom papilla root on the caudal half. arrow, tongue-like filiform papillae; arrowhead, lingual groove; downward-facing dart arrow, lingual rib; upward-facing dart arrow, lingual wall; star, filiform papilla root.

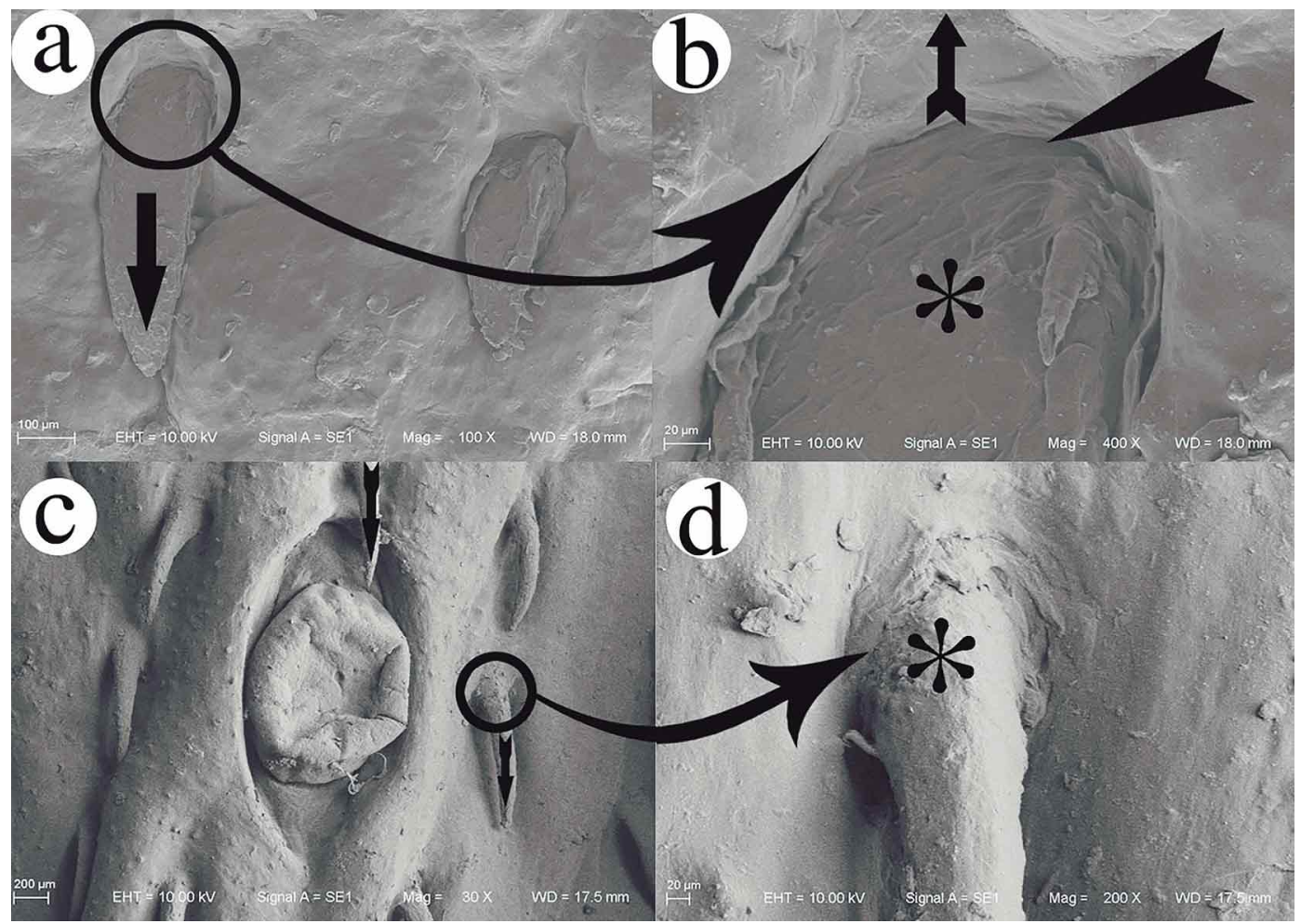

Fig. 4. Filiform papillae on lateral surface of the tongue. (a) Morphology of filiform papillae in the lingual apex. (b) Structure of filifrom papilla root in the lingual apex. (c) Morphology of filiform papillae in the lingual body. (d) Structure of filifrom papilla root in the lingual body. arrow, tongue-like filiform papilla; downward-facing dart arrow, conical filiform papilla; upward-facing dart arrow, lingual wall; arrowhead, lingual groove; star, filiform papilla root. 


\section{DISCUSSION}

This study determined that the tongue of Chinese yellow cattle contains six types of filiform papillae root structures. Five types exhibited lingual grooves, which surrounded the filiform papillae on the dorsal surface of the lingual apex and the body, as well as on the lateral surface of the lingual apex. In previous studies, lingual grooves were detected around the fungiform, vallate, conical, and lenticular papillae in cows (Chamorro et al.; de Paz Cabello et al.), Zavot cattle (Sari et al.), and domestic cattle (Scala et al., 1995; Shao et al.); fungiform and vallate papillae were also observed in buffaloes (Scala et al., 1993) and yaks (Shao et al.; Wang et al.). These structures were also identified around vallate papillae in other ruminants, e.g., Formosan serows (Atoji et al.), deer (Erdogan \& Perez, 2014), and camels (Eerdunchaolu et al., 2001; El Sharaby et al., 2012). Nonetheless, to date, the lingual grooves around filiform papillae have yet to be examined by researchers in the field of bovine lingual morphology.

In the tongue of Chinese yellow cattle, the root structures of the filiform papillae on the dorsal surface of the lingual apex were divided into two types (Figs. 2b and 2d). One type was distributed on the rostral half of the lingual apex and was composed of only a lingual groove (Fig. $2 b)$. The other type was located on the caudal half and consisted of a lingual groove as well as two secondary papillae (Fig. 2d). All the lingual grooves were irregular, and they separated the filiform papillae from the dorsal surface. Chamorro et al. suggested that based on the taste buds, the lingual groove surrounding the fungiform and vallate papillae in cow tongues performed gustatory functions. However, no taste buds were observed in the lingual grooves of the root structures in the tongues of Chinese yellow cattle. Therefore, the function of these lingual grooves may be related to the mechanical motion or structure protection of filiform papillae. Previous research reported that the tongue can grind, capture, and transport forage, given the caudal orientation of filiform papillae (Sari et al.; Kurtul \& Atalgin; Eerdunchaolu et $a l$.). Thus, it was hypothesized that caudally oriented filiform papillae can exert effective for- ce on forage. In the geometric model of root structures (Fig. 5), lingual grooves limited the sway of filiform papilla to a range of q (Fig. 5a). As a result, a driving force was exerted on the forage. Without the lingual groove, the filiform papilla sways in line with a scope of $180^{\circ}$ (Fig. 5c) and an effective driving force will not be induced for the forage. In conclusion, lingual grooves limited the motion range of filiform papillae to capture forage. In addition, two secondary papillae were distributed on the two lateral sides of each filiform papilla root located in the caudal half of the lingual apex (Fig. 2d). These papillae were detected in other ruminants as well; for instance, one to three secondary papillae were observed in Zavot cattle (Sari et al.); two were detected in Formosan serows and chital deer (Atoji et al.; Erdogan \& Pérez); four to eight were observed in lambs (Tadjalli \& Pazhoomand, 2004); and six to eight were detected in goats (Kumar et al., 1998). In the tongue of Chinese yellow cattle, secondary papillae emerged from a lingual groove. This groove can protect both the secondary papillae and the filiform papilla root from damage (Fig. 5b).

In the current research, the root structures of the filiform papillae on the dorsal surface of the lingual body were divided into two types as well (Fig. 3). One type was distributed on the rostral half of the lingual body, and a rib emerged from a lingual groove to make contact with the filiform papilla root (Fig. 3b). The other type was located on the caudal half of the lingual body, and the filiform papilla emerged from a lingual groove to form a low lingual wall (Fig. 3d). Both root structure types exhibited lingual grooves; however, the roles played by these grooves differed from those of the lingual apex. In fact, these roles were related to the functions of filiform papillae. On the lingual body, the filiform papillae constitute a work plane over the dorsal surface of the tongue given their tongue-like appearance and flat orientation (Figs. $3 \mathrm{a}$ and $3 \mathrm{c}$ ). This plane increased the contact area with forage significantly. Thus, this study inferred that the function of filiform papillae was to transport forage on the dorsal surface of the lingual body. Similar conclusions were drawn in research on yaks (Shao et al.; Wang et al.). Furthermore, lingual grooves buried the filiform papilla root (Figs. 6a and 6b) according to the geometric model of root structures (Fig. 6). As a result, the height $\mathrm{L}$ of the work plane over the dorsal surface decreased; in addition, resistance and energy expenditure declined considerably during forage transportation. Forage can easily pass through the filiform papilla, unlike in common root structures (Fig. 6c). The lingual rib strengthened the filiform papilla root (Fig. $6 a)$, and the low lingual wall protected the filiform root from being crushed by forage (Fig. 6b).

Two types of filiform papilla root structures were also observed on the lateral surface of the tongues of Chinese yellow cattle (Fig. 4). The root structures on the lateral surface of the lingual apex were similar to those on the dorsal surface of the caudal half of the lingual body. The structures all displayed grooves with a lingual wall at the filiform papilla root and were important to the protection of such roots. When the tongue extended from the oral cavity, the dorsal surface of the lingual apex captured forage based on the caudally orientated filiform papillae (Shao et al.). At the same time, the lateral surface of the lingual apex 


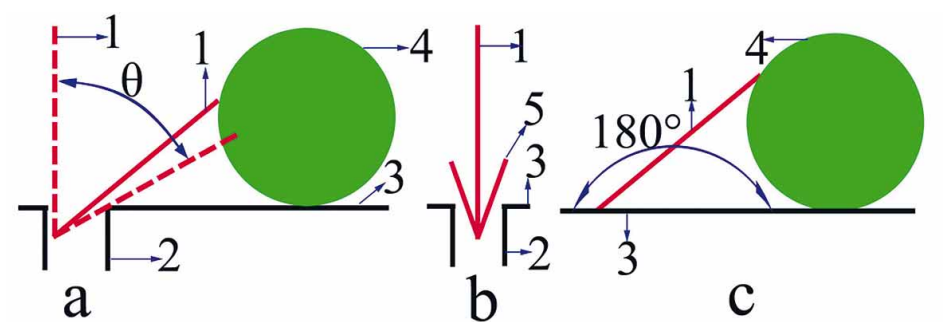

Fig. 5. Geometric model of root structures on dorsal surface of the lingual apex. (a) Tangential model on the rostral half. (b) Anterior model on the caudal half. (c) Tangential model of the common root structure. 1, conical filiform papilla; 2 , lingual groove; 3 , dorsal surface; 4 , forage; 5 , secondary papilla; q, swing angle.

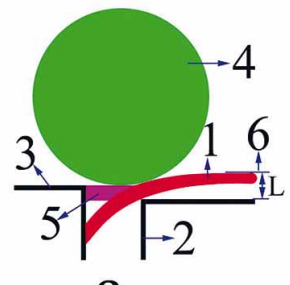

a

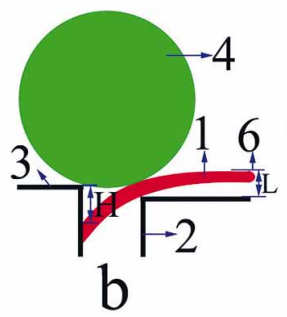

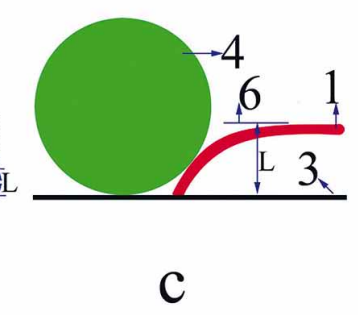

Fig. 6. Geometric model of root structures on the dorsal surface of the lingual body. (a) Tangential model on the rostral half. (b) Tangential model on the caudal half. (c) Tangential model of the common root structure. 1, tonguelike filiform papilla; 2 , lingual groove; 3 , dorsal surface; 4 , forage; 5 , lingual rib; 6 , work plane; $\mathrm{L}$, height of work plane; $\mathrm{H}$, lingual wall.

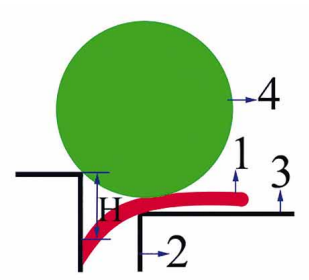

a

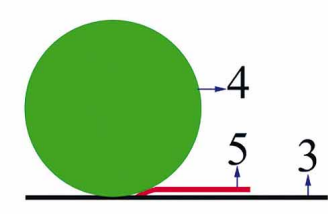

b
Fig. 7. Geometric model of the root structures on the lateral surface of the tongue. (a) Tangential model in the lingual apex. (b) Tangential model in the lingual body. 1, tongue-like filiform papilla; 2, lingual groove; 3, dorsal surface; 4, forage; 5, conical papilla; $\mathrm{H}$, lingual wall.

made contact with the forage. Consequently, the lingual wall can protect the filiform papilla root from damage by forage. To enhance the protection functions for adaption to harsh food environments, the lingual wall formed on the lateral surface was higher than that on the dorsal surface (Figs. 6b and 7a). Moreover, the filiform papillae were tongue-like in appearance, with almost-flat orientations to reduce friction between the forage and the oral cavity.

In this research, the root structures on the lateral surface of the lingual body differed from the five aforementioned types of structures. The former did not exhibit lingual grooves, ribs, walls, or secondary papillae; this type of root structure was observed in yaks (Shao et al.;
Wang et al.) and domestic cattle as well (Scala et al., 1995). During feeding, the lateral surface of the lingual body rarely made contact with forage. Therefore, the filiform papillae examined in the current study did not require a complex root structure for protection. In addition, abundant saliva and liquids were generated in the oral cavity during mastication. A slender and conical appearance can reduce hydraulic resistance in combination with simple root structures (Fig. 7b).

Moreover, the filiform papillae on the lingual apex and body of the tongue of Chinese yellow cattle were classified into two types according to appearance. Conical filiform papillae were distributed on the dorsal surface of the lingual apex and the lateral surface of the lingual body, whereas tongue-like filiform papillae were distributed on the dorsal surface of the lingual body and the lateral surface of the lingual apex. By contrast, conical filiform papillae were uniquely determined in Formosan serows (Atoji et al.), Barbary sheep (Emura et al., 2000), Saanen goats (Kurtul \& Atalgın), goitered gazelles (Harem et al.), giraffes (Emura et al., 2013), and one-humped camels (El Sharaby et al.). Tongue-like filiform papillae were uniquely observed in chital deer (Erdogan \& Pérez), Bactrian camels (Eerdunchaolu et al., 2001), cows (Steflik et al.; Chamorro et al.; de Paz Cabello et al.), buffaloes (Scala et al., 1993), yaks (Shao et al.; Wang et al.), and cattle (Scala et al., 1995). The two types of filiform papillae appearances and cross distributions may induce diverse root structures.

In conclusion, six types of root structures are related to the mechanical functions of filiform papillae in the tongue of Chinese yellow cattle. In combination with the appearances and distributions of filiform papillae, diverse root structures can optimize the lingual mechanical functions and improve their self-protection capabilities. All of the findings described above may be the result of environmental adaption and evolution; moreover, the knowledge regarding the root structures of filiform papillae can lay a foundation for future research on the characteristics and functions of lingual surface in ruminants. To fully understand the morphologic effects of filiform papilla root on the lingual mechanical functions, further experimental studies should be conducted on the microscopic motion and biomechanics of lingual surface during feeding. 


\section{ACKNOWLEDGEMENTS}

This work was supported by the Project of National

Natural Science Foundation of China
(No.51105167\&51475202).
(No.51105167\&51475202).

FU, J.; QIAN, Z. \& REN, L. Efectos morfológicos de las raíces de las papilas filiformes sobre la función mecánica lingual del ganado amarillo chino. Int. J. Morphol., 34(1):63-70, 2016.

RESUMEN: La morfología de las papilas filiformes ubicadas en la raíz lingual del ganado amarillo chino fue estudiada mediante microscopía electrónica de barrido, estableciendo varios modelos geométricos para analizar los posibles efectos de estas estructuras sobre las funciones mecánicas linguales. Se detectaron papilas filiformes cónicas en diversas localizaciones de la superficie lingual, junto con seis tipos de estructuras en la raíz de la misma. Un surco lingual rodeado de las papilas se observó en cinco de estas estructuras. Hasta la fecha, dichos surcos no se han discutido en los estudios sobre la morfología lingual bovina, y aquellas distribuidas en la superficie dorsal de la cúspide lingual pueden limitar los rangos de movimientos en las papilas filiformes. Dos papilas secundarias surgieron de una ranura en la superficie dorsal de la mitad caudal de la cúspide lingual; estas papilas pueden proteger de los daños a una papila filiforme. Las ranuras y la orientación plana de tales papilas en la superficie dorsal del cuerpo lingual pueden reducir el gasto de energía durante el transporte de forraje. Un nervio lingual que puede fortalecer la raíz y las papilas filiformes se observó en una de las ranuras en la superficie dorsal, de la mitad rostral del cuerpo lingual. En la superficie dorsal de la mitad caudal del cuerpo lingual, todas las papilas filiformes generaron una ranura para formar un tipo de paredes linguales que pueden proteger las raíces. Las paredes linguales altas se generaron en la superficie lateral del ápice lingual; estas paredes permiten que las papilas filiformes se adapten a entornos inhóspitos de alimentos. Las estructuras de la raíz en la superficie lateral del cuerpo lingual fueron simples y no mostraron surcos linguales, lo que puede disminuir la resistencia hidráulica durante la masticación. Diversas estructuras de la raíz pueden optimizar las funciones mecánicas linguales y mejorar la capacidad de autoprotección en combinación con el aspecto y las distribuciones de estas papilas. Todas las características antes mencionadas pueden ser el resultado de la adaptación ambiental y la evolución de ganado.

PALABRAS CLAVE: Morfología; Estructura de la raíz; Papilas Filiformes; Función mecánica; Lengua.

\section{REFERENCES}

Atoji, Y.; Yamamoto, Y. \& Suzuki, Y. Morphology of the tongue of a male Formosan serow (Capricornis crispus swinhoei). Anat. Histol. Embryol., 27(1):17-9, 1998.

Cai, D.; Sun, Y.; Tang, Z.; Hu, S.; Li, W.; Zhao, X.; Xiang, H. \&
Zhou, H. The origins of Chinese domestic cattle as revealed by ancient DNA analysis. J. Archaeol. Sci., 41(1):423-34, 2014.

Chamorro, C. A.; de Paz, P.; Sandoval, J. \& Fernandez, J. G. Comparative scanning electron-microscopic study of the lingual papillae in two species of domestic mammals (Equus caballus and Bos taurus). 1. Gustatory Papillae. Acta Anat. (Basel), 125(2):83-7, 1986.

de Paz Cabello, P.; Chamorro, C. A.; Sandoval, J. \& Fernandez, M. Comparative scanning electron-microscopic study of the lingual papillae in two species of domestic mammals (Equus caballus and Bos taurus). II. Mechanical papillae. Acta Anat. (Basel), 132(2):120-3, 1988.

Eerdunchaolu; Takehana, K.; Yamamoto, E.; Kobayashi, A.; Cao, G.; Baiyin, H.; Ueda, H. \& Tangkawattana, P. Characteristics of dorsal lingual papillae of the Bactrian camel (Camelus bactrianus). Anat. Histol. Embryol., 30(3):147-51, 2001.

El Sharaby, A. A.; Alsafy, M. A.; El-Gendy, S. A. \& Wakisaka, S. Morphological characteristics of the vallate papillae of the onehumped camel (Camelus dromedarius). Anat. Histol. Embryol., 41(6):402-9, 2012.

Emura, S.; Okumura, T. \& Chen, H. Morphology of the lingual papillae in the giraffe. Okajimas Folia Anat. Jpn., 89(4):99103, 2013.

Emura, S.; Tamada, A.; Hayakawa, D.; Chen, H. \& Shoumura, S. Morphology of the dorsal lingual papillae in the barbary sheep, Ammotragus lervia. Okajimas Folia Anat. Jpn., 77(2-3):3945,2000 .

Emura, S.; Tamada, A.; Hayakawa, D.; Chen, H.; Yano, R. \& Shoumura, S. Morphology of the dorsal lingual papillae in the blackbuck, Antilope cervicapra. Okajimas Folia Anat. Jpn., 76(5):247-53, 1999.

Erdogan, S. \& Pérez, W. Anatomical and scanning electron microscopic studies of the tongue and lingual papillae in the chital deer (Axis axis, Erxleben 1777). Acta Zool., 95(4):48492, 2014.

Harem, M. K.; Harem, I. S.; Karadag Sari, E. \& Aydin, M. F. Light and Scanning Electron Microscopic Study of the Dorsal Lingual Papillae of the Goitered Gazelle (Gazelle subgutturosa). J. Anim. Vet. Adv., 10(15):1906-13, 2011.

Iwasaki, S. Evolution of the structure and function of the vertebrate tongue. J. Anat., 201(1):1-13, 2002.

Kumar, P.; Kumar, S. \& Singh, Y. Tongue papillae in goat: a scanning electron-microscopic study. Anat. Histol. Embryol., 27(6):355-7, 1998.

Kurtul, I. \& Atalgın, S. H. Scanning electron microscopic study on the structure of the lingual papillae of the Saanen goat. Small Rumin. Res., 80(1-3):52-6, 2008. 
Sari, E. K.; Harem, M. K. \& Harem, I. S. Characteristics of dorsal lingual papillae of Zavot Cattle. J. Anim. Vet. Adv., 9(1):12330, 2010.

Sato, S.; Nagamine, R. \& Kubo, T. Tongue-playing in tethered Japanese Black cattle: diurnal patterns, analysis of variance and behaviour sequences. Appl. Anim. Behav. Sci., 39(1):3947, 1994.

Scala, G.; Mirabella, N. \& Pelagalli, G. V. Morphofunctional study of the lingual papillae in cattle (Bos taurus). Anat. Histol. Embryol., 24(2):101-5, 1995.

Scala, G.; Pelagalli, G.; Vittoria, A. \& de Girolamo, P. Morphostructural study of the lingual papillae in the buffalo (Bubalus bubalus). Anat. Histol. Embryol., 22(3):264-72, 1993.

Shao, B.; Long, R.; Ding, Y.; Wang, J.; Ding, L. \& Wang, H. Morphological adaptations of yak (Bos grunniens) tongue to the foraging environment of the Qinghai-Tibetan Plateau. $J$. Anim. Sci., 88(8):2594-603, 2010.

Steflik, D. E.; Singh, B. B.; McKinney, R. V. Jr. \& Boshell, J. L. Correlated TEM, SEM, and histological observations of filiform papillae of the cow tongue. Acta Anat. (Basel), 117(7):21-30, 1983.

Tadjalli, M. \& Pazhoomand, R. Tongue papillae in lambs: a scanning electron microscopic study. Small Rumin. Res., 54(1-2):15764, 2004.

Wang, J.; Zhang, R.; Zhang, L.; Wang C.; Shao B. \& Wang, J. Histomorphometric adaptation of yak (Bos grunniens) abomasum to the Qinghai-Tibetan Plateau environment. Int. J. Morphol., 33(2):764-76, 2015.
Correspondence to:

Zhihui Qian

Key Laboratory of Bionic Engineering (Ministry of Education)

Jilin University

Changchun, Jilin 130022

CHINA

Tel: +86-13843122197

Fax: +86-0431-85095253

Email: zhqian826@hotmail.com.

Received: 25-09-2015

Accepted: 02-11-2015 